\title{
XLIV. Note on the effect of the replacement of oxygen by sulphur on the boiling- and melting- points of compounds
}

\author{
Miss A. G. Earp
}

To cite this article: Miss A. G. Earp (1893) XLIV. Note on the effect of the replacement of oxygen by sulphur on the boiling- and melting-points of compounds, Philosophical Magazine Series 5, 35:216, 458-462, DOI: $10.1080 / 14786449308620430$

To link to this article: http://dx.doi.org/10.1080/14786449308620430

曲 Published online: 08 May 2009.

Submit your article to this journal $[\pi$

Џll Article views: 2

Q View related articles $\sqsubset$ 


\begin{tabular}{c|c} 
Temperature Cent. & Specific Gravity. \\
\hline 25 & $\cdot 831$ \\
30 & .8306 \\
35 & .828 \\
40 & .826 \\
45 & .8758 \\
50 & .8753 \\
55 & .8717
\end{tabular}

We are now arranging a piece of upparatus which will give, not the absolute value of the specific gravity, but with great accuracy relative rates of the change of specific gravity with temperature *. We shall make experiments of the same kind upon other animal oils.

XLIV. Note on the Effect of the Replacement of Oxygen by Sulphur on the Boiling-and Melting-points of Compounds. By Miss A. G. EARP $†$.

IN

$\mathrm{N}$ various papers published in the Philosophical Magazine $\ddagger$ Carnelley has called attention to the effect produced on the boiling-point and melting-point of compounds by replacing one element in the compound by another belonging to the same group. He gives numerous examples (mostly organic compounds) to show that in the case of the halogen compounds, when one halogen is replaced by another of a higher atomic weight, both the boiling- and melting-point are correspondingly raised.

As a further instance of the same kind of thing he gives the following series of the ethyl carbonates and sulpho-carbonates to show that the boiling-point is raised in proportion to the amount of sulphur introduced in the place of oxygen. He also points out that the same series shows that a definite effect is produced by a change in the arrangement of the molecule without any change in the number of sulphur atoms.

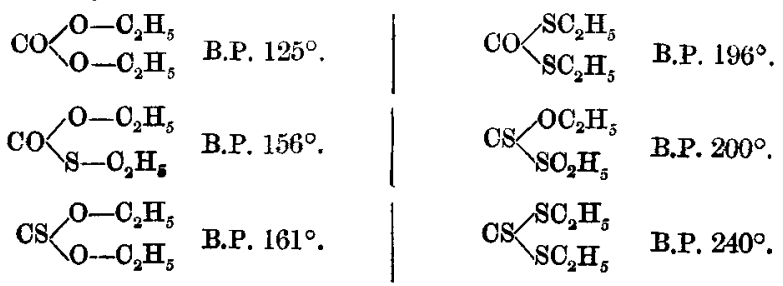

* We described at the Meeting results obtained for other specimens of sperm-oil, with the now apparatus, which exhibited no discontinuity. Yet we can find no reason to doubt Mr. Knight's measurements.

+ Communicated by M. M. Pattison Muir.

$\ddagger$ Phil. Mag. Oct. 1879 . 
He does not, however, mention the way in which this effect is reversed in the cases in which the oxygen of the lydroxyl group is replaced by sulphur, and I therefore conclude that it escaped his notice. By examining the large number of boiling-point data given by him in his tables I have found the following rule to be perfectly general :-

The replacement of oxygen by sulphur in a compound always raises the boiling-point except in those cases in which the oxygen of the hydroxyl group is replaced by sulphur, and then the reverse effect is very marked.

In obtaining data in proof of this I have been confined of course mainly to organic compounds, and of these I have only given the simpler instances, and such of the more complicated compounds as have a known structural formula. The reason for this is obvious, since Kopp has shown that the boiling-point of isomeric hydrocarbons is not the same, showing that a mere rearrangement of the atoms in a molecule is sufficient to affect the boiling-point without any change in number or kind. The fact is further exemplified in the series of ethyl-carbonates given above.

In the following list of compounds containing hydroxyl and their sulphur analogues, it will be seen that the replacement of the $\mathrm{OH}$ by the $\mathrm{SH}$ group always lowers the boilingpoint, and that in the case of bodies of low molecular weight the difference is considerable, but decreases as we ascend a homologous series*.

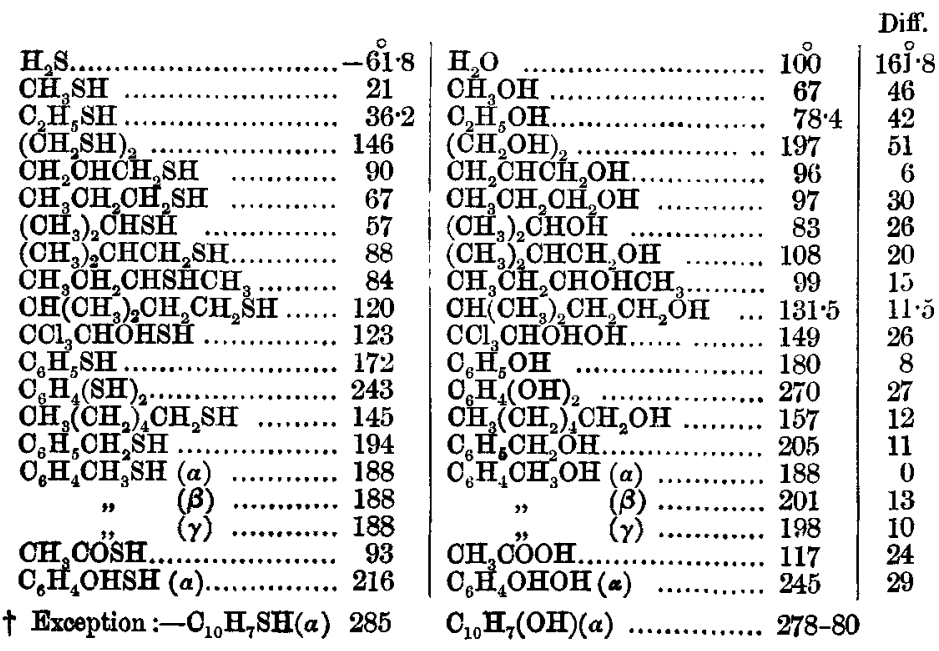

* The only exception to the rule is that marked $\dagger$, and is in the case of a body of high molecular weight and complicated constitution. 
Again, in the following list of compounds containing oxygen not in the condition of hydroxyl, it will be seen that the normal rule is followed.

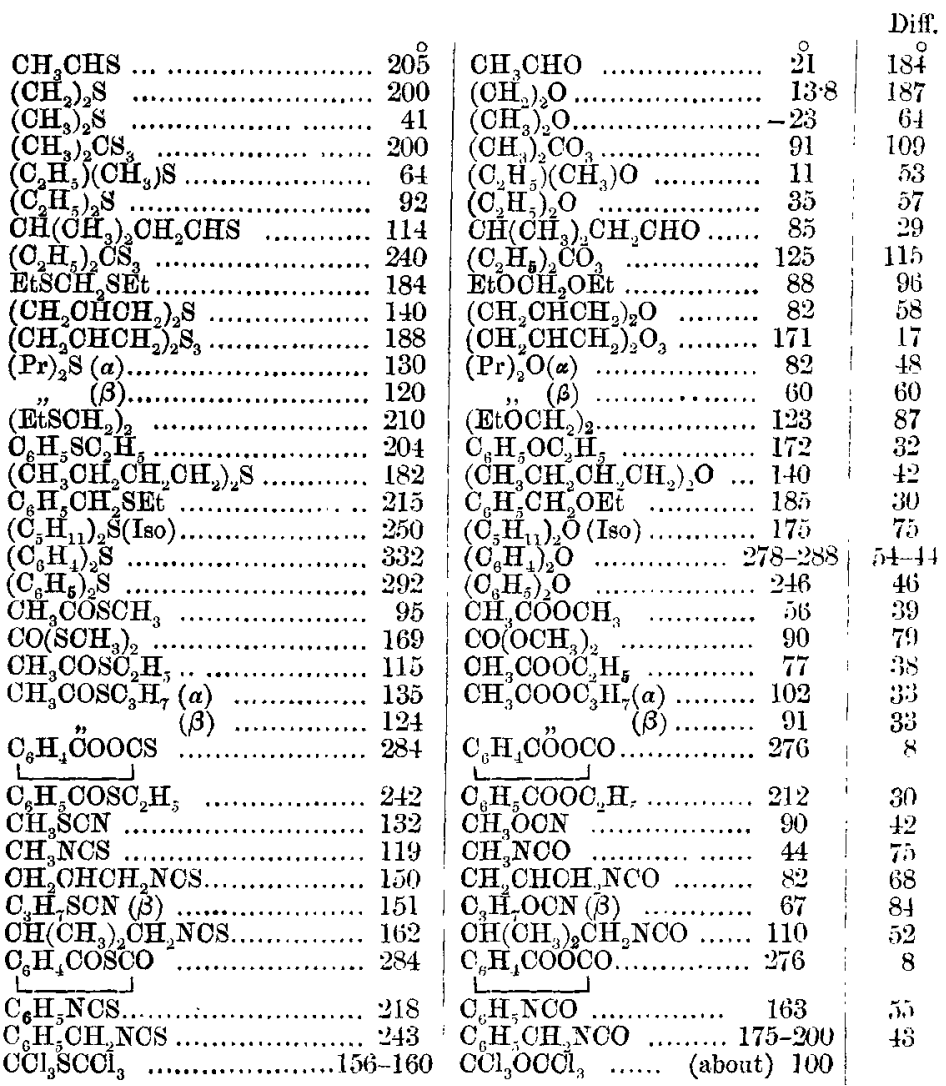

To the above may be added the series of ethyl carbonates quoted at first, and also the following inorganic compound:-

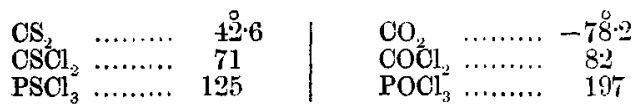

By arranging the data rather differently it is easy to sec that the abnormality lies entirely with the hydroxyl gronl. Thus, if we take any' group of sulphur componnds of one type, we shall find the boiling-point increases with the molecular weight as well when the hydrogen of the SH groul is replaced by a hydrocarbon radical as in any other case. 
Such, for example, are the following :-

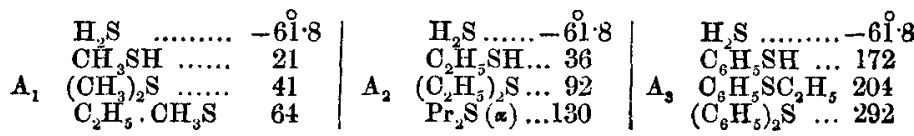

Taking in the same way the corresponding oxygen compounds, we find that by replacing $\mathrm{OH}$ by $\mathrm{OX}$, where $\mathrm{X}$ stands for any hydrocarbon radical, unless very complex, we lower the boiling-point of the compound considerably, whereas when the exchange is simply between different hydrocarbon radicals the change is in the normal direction.

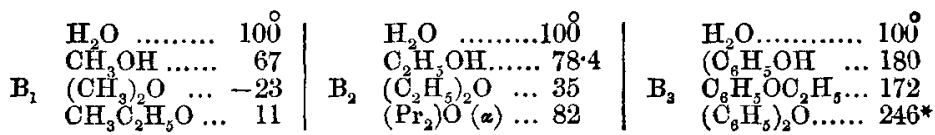

From these data it is evident that the fact that water, which has a lower molecular weight than even any of the " permanent" gases (except hydrogen) will remain liquid up to a very high temperature, is only one particular and wellmarked case of the general effect of the hydroxyl group.

It has been objected by Ostwald and others that the comparison of boiling-points is unsatisfactory, inasmuch as in some cases it is possible that the vapour-pressure curves of different substances may cross one another at some point; and in that case, if some other than atmospherie pressure were taken as the standard, the relative position of the boilingpoints would be reversed.

It is difficult to plot the vapour-pressure curves for $\mathrm{H}_{2} \mathrm{O}$ and $\mathrm{H}_{2} \mathrm{~S}$ on the same scale, since the pressure of $\mathrm{H}_{2} \mathrm{~S}$ varies by many atmospheres; while that of $\mathrm{H}_{2} \mathrm{O}$ varies through the same range only by a few inches, so that it has to be represented on the $\mathrm{H}_{2} \mathrm{~S}$ scale by a line following the zero. The $\mathrm{H}_{2} \mathrm{~S}$ curve is, however, perfectly normal, and shows no tendency whatever to approach the zero at any point short of infinity. Hence the objection about the crossing of the eurves falls to the ground in this case. The same may be shown by comparing the curves for $\mathrm{CO}_{2}$ and $\mathrm{CS}_{2}$; only in this case, of course, the sulphur compound follows the zero line, while the other is highly inclined.

With regard to the melting-points of oxygen and sulphur compounds the same general rule holds; but exceptions are not rare, particularly in the cases of more complicated compounds, and naturally it is among these that the larger number

* In this case the destruction of $\mathrm{OH}$ is not sufficient to balance the effect of introducing the second carbon ring.

Plit. Mag. S. 5. Vol. 35. No. 216. May 1893. 2 I 
of melting-point data are given. In all probability the tendency to form molecular groupings and other unknown factors tend to obscure the effect on melting-points due to the change of constitution alone.

Another point which I think may be noticed with advantage from the series just given on page 461 , and which, as far as I am aware, has been hitherto neglected, is the effect on the boiling-point of the symmetry of the molecule, unsymmetrical molecules tending to boil higher than symmetrical ones.

Consider the series $A_{1}$, page 461 . Between the first and second members of the series there is a large difference, the molecular weight being increased and the symmetry of the molecule destroyed at the same time. Between 2 and 3 of the same series, on the other hand, there is a much smaller difference ; the molecular weight is increased but symmetry is restored, and the two things act against one another.

Again, consider the series $B_{1}$. Between 1 and 2 in this series the destruction of hydroxyl lowers the boiling-point, the destruction of molecular symmetry tends to raise it, the result being that the difference only of the two effects is small. Between 2 and 3 the destruction of hydroxyl and the restoration of symmetry act together, and the resultant effect is large.

The same effects may be noticed by comparing $A_{2}$ and $B_{2}$ in the same way, and also by comparing the first, second, and fourth members in the series $A_{3}$ and $B_{3}$ respectively.

XLV. Notices respecting New Books. An Elementary Treatise on Modern Pure Geometry.

By R. Lachlan. (London: Macmillan. 1893. Pp. $x+288$.)

MR. LACHLAN is a recognized master of the Geometrical I craft, and the work before us well maintains his reputation. His primary object is to meet the new Cambridge Tripos regulations, in which provision is made for the introduction of a paper on "Pure Geometry." All that could fairly be looked for in such a paper is given by the writer, or is led up to by him. He has not, however, contented himself with such a limited supply as this would require, but he has written with a view to allure students on to the arcana of the science. After a careful perusal we have detected very few errata. On page 53, Ex. 4 is obviously a slip, and in line 3 from bottom for $\mathrm{B} x$ read $\mathrm{B} y$, for $\mathrm{C} x$ read $\mathrm{C} z$. Page 55 line 13 contains a small clerical error: the opening 